Meta

Journal des tradlucteurs

Translators' Journal

\title{
Perspectives on Translation from the Firthian Tradition
}

\section{Michael J. Gregory}

Volume 25, numéro 4, décembre 1980

URI : https://id.erudit.org/iderudit/002967ar

DOI : https://doi.org/10.7202/002967ar

Aller au sommaire du numéro

Éditeur(s)

Les Presses de l'Université de Montréal

ISSN

0026-0452 (imprimé)

1492-1421 (numérique)

Découvrir la revue

Citer cet article

Gregory, M. J. (1980). Perspectives on Translation from the Firthian Tradition. Meta, 25(4), 455-466. https://doi.org/10.7202/002967ar d'utilisation que vous pouvez consulter en ligne.

https://apropos.erudit.org/fr/usagers/politique-dutilisation/ 


\section{Perspectives on Translation from the firthian tradition}

Michael J. Gregory

I am not a translator or a translation expert; I am a linguist, a philologist, whose specialities are the description of present-day English, sociolinguistics, and stylistics; but I belong to that tradition of ethnographical, sociologically conscious linguistics that in Great Britain stemmed from the work of J. R. Firth and Bronislaw Malinouski and has resonances with that of Edward Sapir and Kenneth Pike in North America and the Prague School in Europe. The British tradition, particularly as developed and extended by my contemporaries M.A.K. Halliday and, as regards this topic, J. C. Catford, has always been sensitive to the importance of translation and has placed it firmly within the concerns of linguistics.

I have also been encouraged to write this paper because some of my colleagues and students have found my work on language varieties and textual stylistics a help to them when dealing with problems of translation. I wish to refer particularly here to the very fine doctoral dissertation of the Nigerian poet, critic and linguist Oluwaniyi Osundare entitled 'Bi-lingual and Bi-cultural Aspects of Nigerian Prose Fiction ". In this thesis Dr. Osundare makes original and creative use of ideas from the work of Catford and myself to describe the task of combining creation with translation which is the constant challenge facing the black African writer who chooses to create, not in an indigenous language, but in English or French.

As early as 1935 in his seminal paper 'The Technique of Semantics', J. R. Firth stated that "the whole problem of translation is in the field of semantics ${ }^{2 "}$; and for Firth linguistics was semantics, more particularly the semantics of texts. In his 1951 paper 'Modes of Meaning' he wrote "The disciplines and techniques of linguistics are directed to assist us in making statements of meaning" and "the constructs or schemata of linguistics enable us to handle isolates that may be called language events ${ }^{3}$ ". In Firthian terms a text, written (in one form of notation or another), recorded, or remembered, is the abstracted record of a language event; and it is about such records that we want to make statements of meaning and it is texts which we translate. It was, however, axiomatic for Firth that a statement of meaning "cannot be achieved

1. Ph. D. York University, Toronto, 1979.

2. J.R. Firth, "The Technique of Semantics», in Papers in Linguistics 1934-51, London, Oxford University Press, 1957, p. 32.

3. J.R. Firth, op, cit., p. 191 . 
at one fell swoop by one analysis at one level ${ }^{4 "}$. Rather it had to be made in terms of a series of contexts of patterning (or 'modes' or 'levels' as he variously called them). These were the phonetic, the phonological, the grammatical, the collocational (or lexical), and the situational; so for Firth there was phonetic meaning, phonological meaning, lexical meaning and situational meaning and all were involved in the process of translation; about this he was insistent. He was particularly concerned that we should recognize that there was phonetic and phonological meaning; and also what he called 'phonoaesthetic' meaning: that is "the association of social and personal attitudes in recurrent contexts of situation with certain phonological features." In 'Modes of Meaning' we have the oft quoted assertion "the general feature of voice quality is part of the phonetic mode of meaning of an English boy, a Frenchman or a lady from New York. Surely it is part of the meaning of an American to sound like one ${ }^{6}$." Elsewhere in the same paper he links this with translation: "To begin with we must apprehend language events in their contexts as shaped by the creative acts of speaking persons. Whenever a man speaks he speaks in some sense as a poet. Poets have often emphasized that a great deal of the beauty and meaning of the language of poetry is in the sound of it. If that be called the phonological mode of meaning, in poetry it is a mode impossible of translation from one language into another ${ }^{7}$." A little later, having delineated through the different modes what constitutes Swinburnese, "the personal stylistics of the poet", he continues: "...its English quality is in what I have called the lower modes [i.e. phonology and phonetics] and that enables us to understand the common statements that most of Swinburne's poetry is untranslatable into any other language ${ }^{8} . "$

I am not suggesting, by selecting these extensive quotations, that Firth held that because one mode of meaning was not translatable, translation of a text should not be attempted. He is, however, indicating the limits of translatability and the need to search for what his disciple J. C. Catford was later to call "translation equivalents'. This is, I maintain, clear in the following passage from his 1956 paper 'Linguistics and Translation': "... what I may call the total meaning of a text in situation is broken down and dispensed at a series of levels such as the phonological, the grammatical and the situational levels. One can never expect the modes of meaning in a given language to be translatable into parallel or equivalent modes of meaning in a foreign language. This is clearly true at the phonetic or phonoaesthetic level. How should we translate the meaning of alliteration or assonance in English into a language with no such consonant clusters as $\mathrm{sl}, \mathrm{cl}, \mathrm{cr}, \mathrm{str} . .$. ? It is not of course possible on any considerable scale to carry grammatical structures across the bridge of translation. For example, in the English constructions such as your having done that will spoil your chances:

4. J.R. Firth, op. cit., p. 192.

5. J.R. Firth, "The Technique of Semantics», in Papers in Linguistics 1934-51, London, Oxford University Press, 1957, p. 194.

6. J.R. Firth op. cit., p. 192

7. Ibid., p. 193 .

8. J. R. Firth, "The Techniques of Semantics", in Papers in Linguistics 1934-51, London, Oxford University press, 1957, p. 198. 
the non-finite your having done that would require a separate clause with a finite verb in most European languages but it's an important contribution to the technique of translation to know that this must be done $9 . "$

This paper, 'Linguistics and Translation', which he read to an audience at Birbeck College in the University of London in 1956 was Firth's single most cogent and comprehensive statement on the topic of translation, and it ties together many of the ideas presented as asides in other papers.

$\mathrm{He}$ distinguishes four main types of translation : creative translation, official translation, translation as a technique in linguistics (with which I will not be concerned in this paper), and machine translation. What he calls "creative translation" is that which, although inspired by a foreign source, is really intended to be literature in the language into which it is translated. Pope's Illiad, Dryden's Aeneid would be examples of this; Firth's examples are the contrasting "Chinese" poems of Arthur Waley and Ezra Pound. What he calls "official translation" is "exemplified in treaties, international agreements and other institutionalized, controlled and restricted languages $10 "$ " "Restricted language" was a key Firthian concept: it is the language which serves a "circumscribed field of experience or action" and can be seen to have "its own grammar and dictionary "1", what elsewhere has been called a "technical" language 12 . Firth saw linguistics as being at its best when it concentrated on restricted languages; this because the describer can be specific about the contexts of situation and experience in which such texts are embedded; this, in turn, because these contexts are more self-contained, more patterned and recognizably recurrent than the contexts of situation of less circumscribed, more open-ended, varieties of language. The collocational patterning of the vocabulary, the company words keep as lexical items, in the texts of restricted languages, is open to powerful and revealingly succinct description. However Firth warned that "The restricted languages of official translation... have often been the source of international friction, caused by misunderstanding, the misunderstanding, of course, being explained by mistranslation ${ }^{13}$." Firth's example was the possible confusion between English controller, French controleur; in Canada ten to twelve years ago we were having problems with the shared homograph nation. So Firth emphasized the need for "the restriction of research in translation to the circumscribed fields of restricted languages. It is in the study of the restricted languages of science and politics both national and international" he wrote, "that part of the translation problem is met, in the mutual assimilation of the languages in similar contexts of situation ${ }^{14}$."

9. J.R. Firth, "Linguistics and Translation" in Palmer, F.R. (ed.), Selected Papers of J. R. Firth 1952-59. London, Longman, 1968, p. 92.

10. Ihid., p. 86-87.

11. Ibid., p. 87 .

12. Cf. Michael Gregory, "Aspects of Varieties Differentiation", Journal of Linguistics, Vol. 3, p. 177-198, (1967); Michael Gregory and Susanne Carroll, Language and Situation: Language' Varieties in their Social Contexts, London, Routledge \& Kegan Paul, 1978, p. 7, p. 30.

13. J. R. Firth, "Linguistics and Translation », in Palmer, F. R. (ed.), Selected Papers of J.R. Firth 1952-59, London, Longman, 1968, p. 87.

14. Ibid., p. 88 . 
In a 1956 lecture, 'Descriptive Linguistics and the Study of English', given in Berlin to a German audience, he also raised this matter: "The difficulties of translation between two discrepant languages are not so geat if the situations are to some extent common. It is easier to build the bridge from the source language if the situational context is mutually assimilated by cultural convergence ${ }^{15}$."

Problems raised by cultural divergence including the medium resources of two very different languages, and a recognition that restricted languages can be found in literature and creative translation, all make interesting Firth's remarks about the Chinese poems of Arthur Waley and Ezra Pound. He sees that both the language of the Chinese poems from which Waley "derived" his poems (a term Firth prefers in this instance to "translated") and the English Waley "creates" in his version comprise restricted languages as they too serve "a circumscribed field of experience" and have "their own grammar and dictionary". He sees the poet-translator as having to provide an "enrichment" in his own language ${ }^{16}$. Firth is not too explicit about this but I take it that he means that the transference of another, divergent culture into English linguistic expression entails an enrichment of that expression.

Firth then compares treatments of the same Chinese text by Waley and Pound: "Waley presents us with this sentence based on Chinese - to learn and at due times repeat what one has learnt, is not that after all a pleasure? Ezra Pound's version runs study, with the season's winging past, is this not pleasant? In this case situational and other non-linguistic elements have found their way into Waley's version which is not communicating the Chinese but giving us comprehension of the Chinese ${ }^{17}$."

Pound on the other hand, Firth points out, is concerned with the attempt to translate written Chinese characters by finding in their graphic structure something that can be used metaphorically through English grammar and lexis. For example, the Chinese character usually translated as proud, has the caracter high written with the radical horse - so this is a good one for Pound and he gives us high-horsey. But Pound is not always so lucky; study with the season's winging past derives from the character customarily given the translation meaning of repeat. Firth comments tartly: "This character has the wings radical but it is no good thinking of flapping wings here, nor is the mode of meaning of the character structure any help towards an English version ${ }^{18}$." You may think that Firth is being a little tough on Pound in this instance and prefer with the season's winging past to to learn and at due times repeat what one has learnt; however, Firth is not upset that meaning from one mode in Chinese (the graphic) is translated into others (the grammatical and the lexical) in the English metaphor; no, not at all, his concern is that Pound's version does not convey what the Chinese means culturally. He believes that Waley's is much

15. J.R. Firth, "Linguistics and Translation», in Palmer, F.R. (ed.), Selected Papers of J.R. Firth 1952-59, London, Longman, 1968, p. 109-110.

16. Ibid., p. 87.

17. J.R. Firth, «Linguistics and Translation», in Palmer, F.R. (ed.), Selected Papers of J.R. Firth 1952-59, London, Longman, 1968, p. 92.

18. Ibid., p. 92. 
closer to the fully contextualized meaning of the Chinese, Pound's playing around with a no longer contextually relevant possibility of a distant meaning of an element in the graphology is recognized as distorting rather than illuminating, as precious rather than apt.

Utilitarian relevance and pertinency are key Firthian concerns in contextualization. After citing mistranslations from Anglo-Saxon perpetuated and used by distinguished historians such as H.W.C. Davis, and Sir Charles Oman, he continues:

It is well to remember that different disciplines have entirely different attitudes towards the use of translation. For example, the historian and the lawyer. A text for a lawyer must always be contextualized for its present meaning... The historian... must serialize his contexts and must face the interpretation, let us say of the Charter [Magna Carta], not only in its own day but also at each stage... Such contextualizations and comparisons would prevent gross errors of translation... I need only mention the translation of Stubb's Select Charters last century by Smith, the master of Balliol. He appears to have translated Medieval Latin as though it were Ciceronian prose to be rendered by a humanist in contemporary English... The result was such an embarrassment that, after his death, attempts were made to buy up all surviving copies ${ }^{19}$.

Firth also wanted to see research into the role of translation in the history of literature and criticism, and to see sound linguistically oriented studies of the relations between translations and the works of literary giants such as Shakespeare and Milton. He was convinced that Shakespeare was more popular in the theatre in Germany than in England, and he was convinced too, that this was because of the modern translations the Germans were free to use. He told his Berlin audience: "In England producers have tried Hamlet and Macbeth in modern dress, Hamlet in a dinner jacket with a revolver, and Macbeth in khaki. We cannot get the text, however, into linguistic modern dress, and so give it modern meaning in linguistic terms. You can ${ }^{20}$." He was interested too in English and German translations of the Bible and their cultural place; he was confident that the present day use of English expressions which can be referred to Biblical sources and similar ones in German have all moved a long way from the source language in their contexts ${ }^{21}$. The British English expression "he gave up the ghost" would be a good example; it is used now generally in contexts to do with resignation, failure, the non-achievement of a goal. In its original Biblical context, the final cry of a victorious Christ from the cross, the New Testament expression might have had more to do with the "committing" or "handing over" or "delivery" of an unconquered spirit, than with the surrendering of a feeble ghost (such is the opinion of Bishop Ralph Dean) ${ }^{22}$. Again, serial contextualization is in order.

19. J.R. Firth, "Linguistics and Translation", in Palmer, F.R. (ed.), Selected Papers of J.R. Firth, 1952-59, London, Longman, 1968, p. 88-89,

20. J.R. Firth, "Linguistics and Translation», in Palmer, F.R. (ed.), Selected Papers of J.R. Firth 1952-59, London, Longman, 1968, p. 109.

21. Ibid., p. 89 .

22. Bishop Ralph Dean, In the Light of the Cross, Anglican Church of Canada, Toronto, 1961, p. 90-92. 
As will have become apparent, Firth was firmly what he would have called anti-mentalistic. He said: "You have the option of connecting structures and systems of language with structures and systems of thought or with structures and systems in situations comprising the human participants, their nonverbal behavior, the relevant objects and other events and these two alternatives. I suggest - difficult though it may appear - that the situational matrix is the more manageable one and more easily related to problems of translation ${ }^{23}$." So it was that he actively encouraged translators to introduce into the target language, specific references when these were necessary for a good effort at translation equivalence. I suggest that the principle and a good deal of the practice behind Dr. Kenneth Taylor's paraphrased "translation", The Living Bible, would have gained his support; its theological standpoint he might not have found so congenial.

Machine translation he confessed he knew little about. He recognized that a human translator could be tought of as a machine but, with a salutory good sense not shared by all linguists, he pointed out that "the trouble is that we do not know how it works ${ }^{24}$ ". His hunch was that the best progress in machine translation would be made by the study of long units rather than the minimal segments favoured at that time by many of his transatlantic colleagues, and also by the examination of the mutual expectancy of words in cliches and high frequency collocations, particularly within restricted languages.

In 1965, a follower of Firth's, J.C. Catford published A Linguistic Theory of Translation ${ }^{25}$. This is a lucid, succinct and penetrating little book. It was based on lectures given in the School of Applied Linguistics in Edinburgh University and its concern was not directly with special problems of translation, but with the analysis of what translation is; and as such it very healthily cleanses the corridors of thought about the activity of translation. "It sets up... tentatively... a theory of translation which may be drawn upon in any discussion of particular translation problems ${ }^{26}$." Translation as a process is seen as unidirectional : performed in a given direction from a Source Language to a Target Language; and so is defined as follows: "the replacement of textual material in one language (the Source Language) by equivalent textual material in another language (the Target Language) ${ }^{27}$. "Textual material" and "equivalent" are crucial terms and need comment :

Textural material is used rather than "text" to cater for the fact that normally it is not the linguistic entirety of a Source language text which is translated; that is, replaced by Target language equivalents. Simple replacement by Target language material may be taking place at one or more levels of language. For example, if we translate the English text What time is it? into French as Quelle heure est-il? there is replacement of SL (English) grammar and lexis by equivalent TL (French) grammar

23. J.R. Firth, "Linguistics and Translation", in Palmer, F.R. (ed.), Selected Papers of J.R. Firth 1952-59, London, Longman, 1968, p. 91.

24. Ibid., p. 93

25. J.C. Catford, A Linguistic Theory of Translation, London, Oxford University Press, 1965.

26. Ibid., p. vii.

27. Ibid., p. 20. 
and lexis. There is also replacement of SL graphology - but the TL graphological form is by no means a translation equivalent of the $\mathrm{SL}$ graphological form. ${ }^{28}$

In discussing translation equivalence Catford distinguishes between it as an empirical phenomenon, and as a theoretical consideration. Empirically, equivalence is discovered by comparing Source language and Target language by way of an informant or informants and by way of commutation and observation of concomitant variation. Theoretically we are interested in the underlying conditions or justification of translation equivalence ${ }^{29}$.

Source language and Target language terms only rarely have "the same meaning" in the linguistic sense of the word; what they do is function in the same situation: "SL and TL texts or items are translation equivalents when they are interchangeable in a given situation ${ }^{30}$." Catford asserts that this is why translation equivalence can nearly always be established at sentence rank: "the sentence is the grammatical unit most directly related to speech function within a situation ${ }^{31}$." Here we have an echo of Firth's point that the larger units are likely to yield most in the translation process, and a link with Prague School ideas of Functional Sentence Perspective. Close to Firth too and more explicit, is Catford's approach to the question of meaning and translation. "Meaning in our view," he writes "is a property of a language... a Russian text, for instance, has a Russian meaning (as well as Russian phonology/graphology, grammar and lexis) and an equivalent English text has an English meaning. This is necessarily the case since, following Firth, we define meaning as the total network of relations entered into by any linguistic form ${ }^{32}$." Grammatical and lexical items enter into relations of two kinds, formal relations and contextual relations. Formal relations are concerned with the structural and systemic possibilities of items grammatically, and their collocational potentialities and set membership lexically - and they yield the formal meaning of an item. But grammatical and lexical items also have contextual relations; they are relationships to relevant elements in the situations in which they operate as, or in, texts. Now as every language is formally sui generis and any formal correspondance between languages, approximate, it follows that formal meanings of Source Language items and Target Language items are only occasionally the same. French $j^{\prime} a i$ merai may on many occasions be the translation equivalent of English I'll love, but the units in the two languages enter into very different sets of systemic choices. Their formal meaning derives from the range of grammatical and lexical choices they enter into their own language and so theoretically we cannot talk about formal meaning being transferred from Source Language to Target Language; so, too, of contextual meanings. The grouping of relevant situational features for an item is also related to formal meaning. To exemplify this Cat-

28. J.C. Catford, op. cit., p. 20.

29. J.C. Catford, A Linguistic Theory of Translation, London, Oxford University Press, 1965, p. $27-28$.

30. Ibid., p. 49

31. Ibid., p. 49 . 32. J.C. Catford, A Linguistic Theory of Translation, London, Oxford University Press, 1965 ,
p. 35 . 
ford draws our attention to the systems demonstratives enter into in Standard English and North-Eastern Scots ${ }^{33}$. The Standard English system is contextually two-dimensional ; it involves two degrees of "demonstrativeness", this an these opposed to that and those and two numbers, singular and plural, this and that opposed to these and those. The North-Eastern Scots system is contextually uni-dimensional, involving demonstrativeness: three degrees this time - this, that and yon. Numerosity is then a contextually irrelevant feature of situations for the North-Eastern Scots system. Catford sums it up: "It is clear that if we translate from Standard English to Scots we cannot "transfer meaning". There is no way in which, for example, Scots that can be said to "mean the same" as English that or this or these or those. On a given occasion it may refer to, or be relatable to the same feature of the situation as one of the English [demonstratives]... but its formal and contextual meaning is clearly different ${ }^{34}$."

It is appropriate now for us to examine briefly two other aspects of neoFirthian linguistics which are still developing and which have important implications for translation. The first concerns the nature of text, which is what Firth saw linguistics and translation as being all about. A text is a piece of language that forms a unified whole; it is not just a collection of unrelated sentences; it has what M.A.K. Halliday and R. Hasan in their book Cohesion in English ${ }^{35}$ call the quality of "texture" and it derives this texture from the fact that it functions as a unity with respect to its environment. Internally, a text can be seen to hang together by way of a set of semantic features which are cohesive. Cohesion is present when the interpretation of an element in the text presupposes something other than itself and that something is also explicitly realized in the text. Then the two elements, the presupposing and the presupposed form part of the same text, and constitute a cohesive tie. In English reference, ellipsis, substitution, conjunction and lexical cohesion are the sources of text formation beyond sentence boundaries. Work is still in progress, or not yet begun as regards the particulars of how other languages signal, in their own way, that one has text and not just a collection of sentences. The importance of this kind of work for translation equivalence recognition can hardly be overestimated.

There has also, during the last fifteen years, been considerable work done on the concept of, and description of, varieties within a language. This was inspired by Firth's frequent remarks about restricted languages and is keenly relevant to questions of translation. Catford himself pointed out that "The concept of a 'whole language' is so vast and heterogeneous that it is not operationally useful for many linguistic purposes, descriptive, comparative and pedagogical. It is therefore desirable to have a framework of categories for the classification of sub-languages or varieties within a total language ${ }^{36}$." In

33. J.C. Catford, A Linguistic Theory of Translation, London, Oxford University Press, 1965, p. 37

34. Ibid., p. 37.

35. M.A.K. Halliday \& R. Hasan, Cohension in English, London, Longman, 1976.

36. J.C. Catford, A Linguistic Theory of Translation, London, Oxford University Press, 1965, p.88. 
several publications ${ }^{37}$ colleagues and I have attempted to explicate and develop such a framework, and our terminology and schemata have been widely accepted. Some of the categories which we use are of long standing in philological study: these are those which are related to constant features of users in language situations. Temporal, geographical and social dialects are sets of linguistic habits corresponding to the temporal, geographical and social provenances of speakers and writers. Idiolect is the individual dialect: the variety related to the personal identity of the user. It is not always necessary to translate idiolects; the personal identity of the user may not be relevant situationally; it usually is not, for example, in scientific or "official" texts; however, this is not always the case, particularly in plays and novels. Many of Shakespeare's greatest characters are strongly marked linguistically as individuals: Richard III, Falstaff, Hamlet, Iago, Juliet's Nurse, Beatrice, Cleopatra, to mention but a few; and the work for Dickens is full of linguistic curiosities. In such instances I suggest that in the search for "equivalence" the translator has a responsibility to try to distinguish them linguistically as individual in the Target Language; of course, the markers of individuality will not be "the same" or probably even parallel in the two languages.

Dialects themselves can also present translation problems. Many languages, as Catford points out ${ }^{38}$ have a "standard" or literary dialect which shows only slight variation (in its written form at least) from one locality to another and over long stretches of time. For translation purposes it may be regarded as unmarked and unmarked text in the unmarked dialect of the Source Language can usually be translated into an equivalent unmarked Target Language dialect. If there is no such dialect the translator may have the exciting task of helping to create a literary dialect for the Target Language.

When a text has passages in a dialect other than the unmarked dialect, and this is not uncommon in literary works, particularly in the dialogue of novels and plays, the tranlator may have to select an equivalent Target Language dialect. Care and good sense is necessary. In relation to the dialects of the British Isles, Cockney is a south-eastern geographical dialect. However, in translating Cockney dialogue into French French, most translators would quite rightly select Parigot, which is a northerly dialect of French. Catford has pointed out that "the criterion here is the 'human' or 'social' geographical one of 'dialect of the metropolis' rather than a purely locational criterion ${ }^{39}$ ". Interesting here too is that Cockney is marked chiefly by phonological features presented in conventionalized graphological forms, while Parigot is marked chiefly at the lexical level in the use of argot items. In Catford's terms the translation equivalence is set up in this instance between varieties of language not between phonological and lexical features as such.

37. vide. John Spencer \& Michael Gregory, "An Approach to the Study of Style," in N. Enkvist, J. Spencer \& M. Gregory, Linguistics and Style, London, Oxford University Press, 1964; Gregory op. cit., 1967; J. Benson \& W. Greaves, The Language People Really Use. Agincourt, Ontario, Book Society of Canada, 1973; Gregory \& Carroll, 1978, op. cit.

38. J.C. Catford, A Linguistic Theory of Translation, London, Oxford University Press, 1965 , p. 38 .

30. Ibid., p. 87-88. 
A propos of temporal and geographical dialects, it is interesting to note that in a recent study ${ }^{40}$ of modern Canadian fiction, Anthony Tilly has indicated the aesthetic importance of what might be called "generational" dialects along the temporal dimension and of the contrast between "urban" and "rural" geographically. This presents another fascinating challenge to the translator of literature.

Newer categories than dialect relate to constant features of speakers' and writers' use of language in situations; these are the diatypic varieties: field, mode, and personal and functional tenors of discourse and the more abstract and powerful concept of register. In Language and Situation, Suzanne Carroll and I described field of discourse as the linguistic "consequence of the user's purposive role" in the language event, "what his language is about, what experience he is verbalizing ${ }^{41}$ ". This means, among other things, that languages such as English and French which reflect highly developed scientific and technical cultures and a world experience, have a wide variety of strongly marked fields of discourse, particularly as regards their lexis. Even such an ancient language as Hindi faces the problem of creating equivalent scientific and technical fields of discourse, as also does Hausa as it emerges more and more as a national language in Nigeria; on the other hand English has problems coping with "the myriad praise names of the Yoruba $O b a$ " and the complex generic - semantic structure of surrounding $i s u$, Yoruba for yam ${ }^{42}$. Firth's proposed situation-inclusive translation may be the only answer in such cases.

Modes of discourse are the linguistic consequences of users' relationships to language's two mediums, speech and writing. The relationship can initially be seen as the simple one of which is being used, but as soon as we consider relationships such as those between lectures and articles, between conversations in real life and dialogue in novels, and especially plays, distinctions amongst modes of discourse, if they are to be useful and revealing, have to be more delicate than the simple spoken-written dichotomy. Within speaking I have distinguished between speaking spontaneously or non-spontaneously ${ }^{43}$. Spontaneous speech may be conversing, that is when there is the expectation of verbal exchange, or monologuing (where there is no such expectation). Non-spontaneous speech is more complex. It may be reciting, a technical term for the performance of what belongs to an oral tradition, or it may be the speaking of what is written. What has been written may itself have been written to be spoken as if not written, as are the scripts of plays and films, much radio and television, or just written to be spoken with no such pretence, as are most lectures and some sermons. In English texts my colleagues and I have examined there are significant lexical and grammatical, as well as phonological markers of these sub-

40. George Anthony Tilly, Canadian English in the Novels of the 1970's, Ph. D. York University, Toronto, 1980 .

41. M. Gregory and S. Carroll, Langhage and Situation :

41. M. Gregory and S. Carroll, Language and Situation: Language Varieties in their Social Contexts. London, Routledge \& Kegan Paul, 1978, p. 7.

42. O. Osundare, Bilingual and Bicuttural Aspects of Nigerian Prose Fiction. Ph. D. York University, Toronto, 1979, p. $123,127$.

43. M. Gregory \& S. Carroll, Language and Situation: Language Varieties in their Social Contexts, London, Routledge \& Kegan Paul, 1978, p. 39-45. 
modes of speech; it is, however, unfortunate how many poor translations of the classics of European theatre there are in English, translations which have, as Firth might have said, no implication of utterance in English, although they might pass as written texts.

Tenors of discourse result from the mutual relations between the relationship the user has with his audience, and the language used. When the relationship is looked at as a personal one, variations in English and other languages can be seen to range from extreme degrees of formality to similar degrees of informality by way of virtually unmarked norms. These are what are known as personal tenors of discourse. When the relationship is viewed functionally, concerned with what the user is trying to do with language to his audience, whether he is teaching, persuading, amusing, controlling and so on, we can discern functional tenors of discourse. Tenor of discourse is certainly an area in which the translator has to keep his head. A North American young man may easily talk to his father is an informal personal tenor; indeed his father might suggest he was being "taken for a ride" if he did otherwise; but an Oriental young man may have to use honorific forms in such a situation. Certainly filial respect and affection are likely to be both present in both situations but respect is usually not linguistically relevant for the North American in this situation; it is for most Orientals. The translator has to decide what sort of equivalence he wants here. If, translating into English, he uses a formal English tenor, he would probably do well to use it consistently so the reader begins to appreciate that in the particular culture the book is about, this formality of language is the norm in that situation.

In some cases a change of personal tenor involves a corresponding change of dialect or even language; classical Arabic is not really compatible with an informal tenor; and some of the most proficient Nigerian users of English have problems with the more informal tenors - indeed when they do use them they often sound curiously old-fashioned as though they have stepped out of a novel about the Bright Young Things of the 'twenties' or 'thirties', by P.G. Wodehouse or Evelyn Waugh. That may be where they have picked up their informal repertoire rather than in day to day interchange. Several Nigerian colleagues and students of mine have told me that most English speaking Nigerians switch to their indigenous language when speaking informally at home and with friends; and my own observation in Nigeria bears this out. This means that they are not as experienced in informal tenors as they are in other varieties of the language and this influences their creative writing and their creative translations.

There remains one other important category concerned with language varieties, that of register. Many texts can be located similarly as regards field, modes and tenors : lectures on geography, sermons, cooking recipe books, legal depositions, sports reports - such recurring configurations of field, mode, personal and functional tenor constitute registers, the varieties according to use of which a given text is an instance. M.A.K. Halliday has aptly pointed out that "There's not a great deal one can predict about the language that will be 
used if one knows only the field of discourse or only the mode or the tenor. But if we know all three when we can predict quite a lot ${ }^{44}$." Register is, therefore, an important sociolinguistic and semantic concept with pertinent relevance to translation. Consistency of register together with what has been referred to as internal cohesion is what makes a text hang together, function as a unit in its environment. Halliday has abstractly described register as "the configuration of semantic resources that the member of a culture typically associates with a situation type. It is the meaning potential that is [linguistically] accessible in a given social context ${ }^{45}$.

The establishment of register equivalence can be seen then as the major factor in the process of translation; the problems of establishing such equivalence, a crucial test of the limits of translatability.

But I prefer to end with not quite such a neat statement. In his "synopsis of Linguistic Theory" Firth used a nice metaphor: "Do we really know how we translate or what we translate?... Are we to accept 'naked ideas' as the means of crossing from one language to another... Translators know they cross over but do not know by what sort of bridge. They often recross by a different bridge to check up again. Sometimes they fall over the parapet into limbo. There is a good deal of smuggling and surreptitious evasion and deliberate jettisoning of embarassing difficulties ${ }^{46}$."

Perspectives on translation from the Firthian tradition of linguistics may be a little puritanical; we have scant time for 'naked ideas' and look askance at 'smuggling' and 'surreptitious evasion'; but we have tried to build bridges between linguistics and translation because we believe that the humanistic science which studies such a central part of our individual and social behaviour as language should be of some use to men and women.

44. M.A.K. Halliday, Language as a Social Semiotic: the social interpretation of language and meaning, London, Edward Arnold, 1978, p. 223.

45. Ibid., p. 111 .

46. J.R. Firth, The Technique of Semantics, in Papers in Linguistics 1934-51, London, Oxford University Press, 1957. p. 197. 